
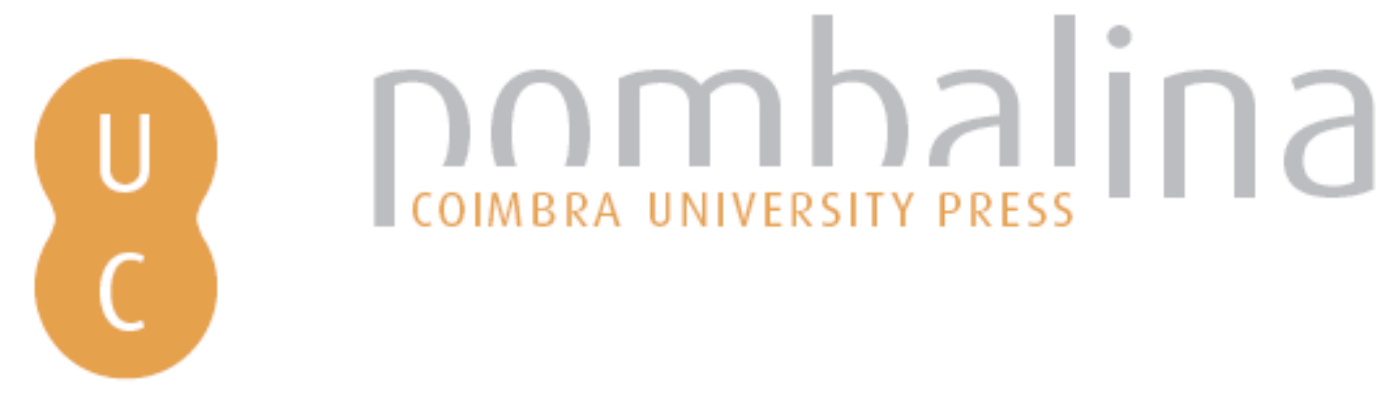

\title{
Vivências, vozes e testemunhos dos alunos dos programas de doutoramento em parceria com o Centro de Estudos Sociais (CES)
}

\author{
Autor(es): $\quad$ Carvalho, Maria José Paiva Fernandes \\ Publicado por: Imprensa da Universidade de Coimbra \\ URL \\ persistente: URI:http://hdl.handle.net/10316.2/36996 \\ DOI: $\quad$ DOI:http://dx.doi.org/10.14195/978-989-26-1045-0_25 \\ Accessed : $\quad$ 26-Apr-2023 11:38:06
}

A navegação consulta e descarregamento dos títulos inseridos nas Bibliotecas Digitais UC Digitalis, UC Pombalina e UC Impactum, pressupõem a aceitação plena e sem reservas dos Termos e Condições de Uso destas Bibliotecas Digitais, disponíveis em https://digitalis.uc.pt/pt-pt/termos.

Conforme exposto nos referidos Termos e Condições de Uso, o descarregamento de títulos de acesso restrito requer uma licença válida de autorização devendo o utilizador aceder ao(s) documento(s) a partir de um endereço de IP da instituição detentora da supramencionada licença.

Ao utilizador é apenas permitido o descarregamento para uso pessoal, pelo que o emprego do(s) título(s) descarregado(s) para outro fim, designadamente comercial, carece de autorização do respetivo autor ou editor da obra.

Na medida em que todas as obras da UC Digitalis se encontram protegidas pelo Código do Direito de Autor e Direitos Conexos e demais legislação aplicável, toda a cópia, parcial ou total, deste documento, nos casos em que é legalmente admitida, deverá conter ou fazer-se acompanhar por este aviso.

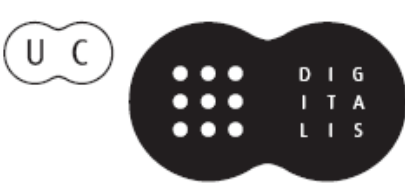



Tendo como pano de fundo as Comemorações dos seus 500 anos, a Biblioteca Geral da Universidade de Coimbra organizou um Congresso Internacional subordinado ao tema "A Biblioteca da Universidade: permanência e metamorfoses", que teve lugar nos dias 16, 17 e 18 de janeiro de 2014, no auditório da Reitoria da Universidade de Coimbra.

O objetivo maior desta reunião científica foi o de refletir sobre o presente e o futuro das bibliotecas que servem públicos universitários. Numa outra vertente, procurou chamar-se a atenção para a importância de que a Biblioteca se reveste, tendo em vista o progresso do conhecimento técnico e científico. Por último, o Congresso pretendeu instituir-se como oportunidade de reflexão prospetiva e como lugar de encontro entre as sensibilidades de todos os que trabalham profissionalmente com livros e com outros suportes de natureza bibliográfica.

Nesse sentido, foram apresentadas Conferências, Mesas Redondas e sessões de Testemunhos em torno de temas como o valor das bibliotecas universitárias, a biblioteca universitária em contexto; as mudanças e os desafios; a biblioteca universitária e a sociedade da informação e conhecimento; o impacto do acesso aberto na comunidade científica, e as bibliotecas digitais. 
MARIA JOSÉ PAIVA FERNANDES CARVALHO

Universidade de Coimbra

\section{VIVENCIAS, VOZES E TESTEMUNHOS DOS ALUNOS} DOS PROGRAMAS DE DOUTORAMENTO EM PARCERIA COM O CENTRO DE ESTUDOS SOCIAIS (CES)

Antes de mais, agradeço ao Sr. Professor José Augusto Bernardes, Diretor da BGUC, o convite que me endereçou para participar no evento das Comemorações dos 500 anos da Biblioteca da Universidade de Coimbra e aproveito para cumprimentar os membros da Comissão Organizadora, os/as conferencistas, colegas e o público, em geral. É meu privilégio apresentar este pequeno contributo em resposta a esse convite.

Antes de iniciar a minha comunicação propriamente dita, porque a minha amiga Kátia Cardoso, doutoranda do CES, me alertou para a coincidência, chamo a vossa atenção para a sigla BUC (Biblioteca da Universidade de Coimbra), cuja fonética se confunde com a fonética da palavra inglesa Book. Esta não deixa de ser uma coincidência interessante já que, para além de pretendermos celebrar a(s) história(s), os momentos, as pessoas, é também de acervos bibliográficos e de livros (books) que falamos, a propósito dos 500 anos da Biblioteca da Universidade de Coimbra, tendo em conta o "valioso acervo (rondando dois milhões de livros, manuscritos e incunábulos), a torna na maior Biblioteca universitária de todo o mundo lusófono"1.

Compete-me, aqui, falar de uma mais recente e mais modesta biblioteca; a Biblioteca Norte|Sul do Centro de Estudos Sociais ou BNS, como

1 Biblioteca Geral da Universidade De Coimbra - Quinhentos anos de Biblioteca da Universidade de Coimbra: uma celebração justa e necessária. [Em linha]. Coimbra: BGUC. [Consult. 5 jan. 2014]. Disponível na WWW em: <URL: http://www.uc.pt/bguc/500anos/ Apresentacao $>$. 
é mais conhecida. A BNS pretende oferecer um acervo bibliográfico alternativo - prioritariamente, mas não exclusivamente constituído por monografias e publicações periódicas - resultante da produção científica realizada nos países do hemisfério Sul (o chamado "terceiro mundo") na área das ciências sociais e humanas, a qual, em geral, é pouco conhecida nos países do Norte. Comporta uma ampla variedade temática: povos indígenas; lutas contra-hegemónicas; identidades e etnicidades; direitos humanos e outros princípios de dignidade humana; questões económicas, organizacionais e empresariais; desenvolvimento democrático sustentável; conhecimentos alternativos e biodiversidade; alternativas à globalização neoliberal; justiça social e inclusão social; estudos feministas e questões de diferença sexual. Inclui ainda produção científica dos países do Norte sobre os países do Sul e é um projeto em fase de expansão como se pode ver pelo gráfico de crescimento do acervo entre 2002 e 2013.

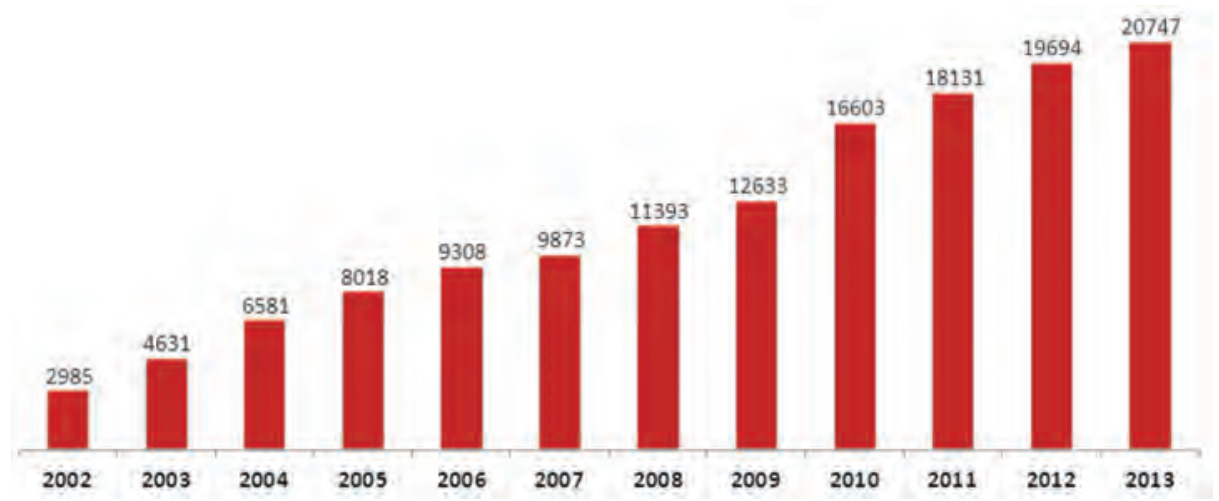

GRÁFICO 1: Crescimento do acervo monográfico (2005-2013)

\section{Introdução}

Perante o tema de trabalho que me foi proposto, "dar um testemunho" enquanto bibliotecária que colabora com o Serviço Integrado das Bibliotecas da Universidade de Coimbra (SIBUC), concluí que a partilha de uma experiência pessoal seria sempre demasiado "umbilical", pela proximidade entre o exercício da profissão e as próprias bibliotecas. 
Pareceu-me mais expressivo obter os testemunhos de quem, dia após dia busca respostas nos nossos recursos bibliográficos, físicos e humanos, validando os 500 anos da Biblioteca da Universidade de Coimbra (BUC) e a existência das bibliotecas a ela associadas. Criada em 1998, a BNS não existe em vácuo! Ela existe em articulação com o SIBUC, é parceira de todas as bibliotecas da Universidade de Coimbra e dialoga com a diversidade de utilizadores neste meio de ensino superior, constituindo-se como um espaço de interação multilinguística e multicultural. Assim, com o intuito de melhor compreender o valor das bibliotecas da Universidade Coimbra, em geral, e da Biblioteca Norte|Sul em particular, e as relações estabelecidas entre os alunos dos programas de doutoramento do CES e as referidas bibliotecas, pediu-se a colaboração destes alunos em forma de testemunho. A estratégia para recolha da informação passou pelo contacto direto, em pessoa e por correio eletrónico, com os alunos do CES, uma comunidade de grande diversidade geográfica, linguística e cultural constituída por portugueses e estrangeiros, provenientes de países como Argentina, Bélgica, Brasil, Cabo Verde, Colômbia, Itália, Rússia, etc., que aqui partilham as suas memórias e vivências, dando voz a quem, hoje, recorre aos serviços das bibliotecas da UC.

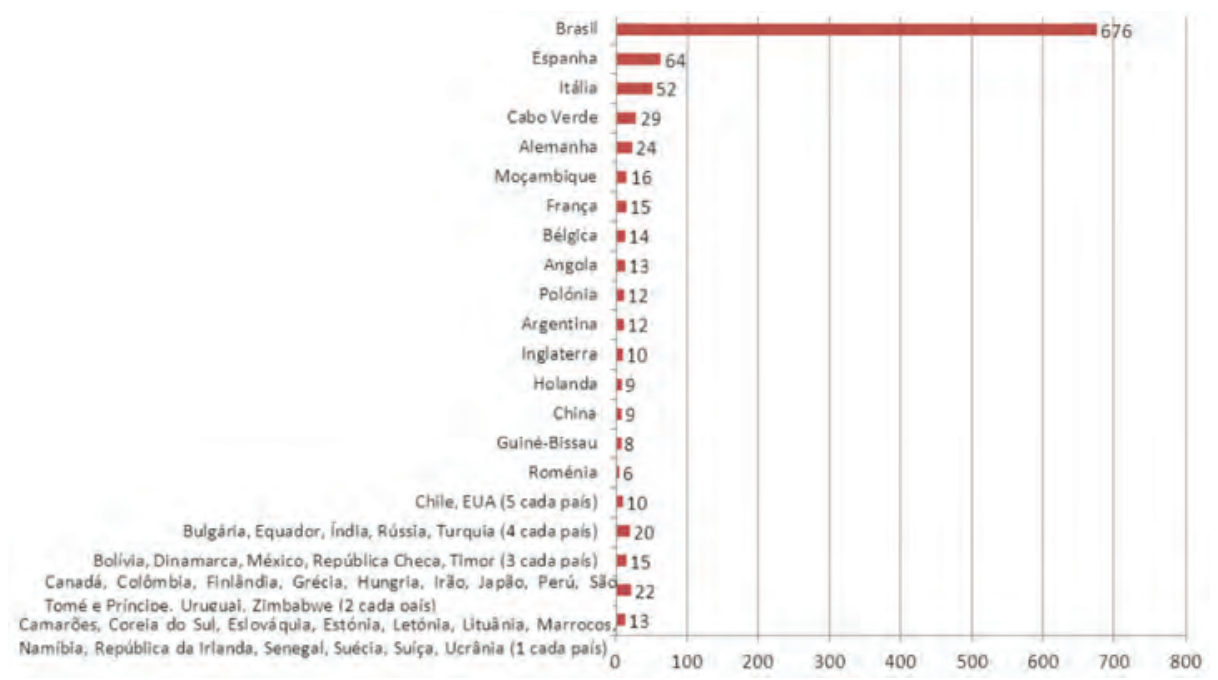

GRÁFICO 2: Total de utilizadores estrangeiros por país (2005-2013) 
A confirmar o como as nossas bibliotecas foram e são "frequentada(s) por gerações sucessivas de investigadores, nacionais e estrangeiros... ${ }^{2}$, apresentamos o testemunho de Olga Solovova, uma doutoranda da Universidade de Coimbra, originária da Rússia, que ilustra bem como as nossas bibliotecas são espaços de confluência de uma comunidade académica diversificada:

"Ao longo dos meses a trabalhar na BNS acabo por ir fazendo observação participante do multilinguismo na biblioteca:

- A ouvir pessoas a falar em português, russo, ucraniano, inglês, francês, espanhol, italiano, finlandês e mandarim, em várias vozes, registos e sotaques;

- A ver as escritas que coabitam o espaço em ação: em românico, em cirílico, em caracteres chineses.

Hoje tive uma experiência inédita de corrigir um texto redigido em português por uma mestranda macaense, a comentar em inglês e português (!)

Coimbra em plena superdiversidade!”3

Qual a perceção dos utilizadores no que concerne ao valor das nossas bibliotecas?

As bibliotecas universitárias, em geral, e as bibliotecas dos Centros de Estudos Avançados, em particular, desempenham um papel vital no processo de formação dos seus utilizadores. Assim é o caso da Biblioteca Norte|Sul, onde os utilizadores, internos e externos, e o apoio personalizado se estabelecem como prioridades. Através de um plano de formação individualizada, dada no momento da chegada, tendo em conta a ampla diversidade linguística e cultural dos utilizadores, com o objetivo

2 Biblioteca Geral dA UNIVERSIDAdE DE COIMBRA - Quinhentos anos de Biblioteca da Universidade de Coimbra: uma celebração justa e necessária. [Em linha]. Coimbra: BGUC. [Consult. 5 jan. 2014]. Disponível na WWW em: <URL: http://www.uc.pt/bguc/500anos/ Apresentacao $>$.

3 Работая в библиотеке нашего центра, наблюдаю неуклонный рост многоязычия.Посетители и сотрудники библиотеки общаются между собой на португальском, английском, французском, испанском, немецком, русском, украинском, финском и китайском - все это вразноголосьи стилей, акцентов и говоров. Переписываются же они с помощью латиницы,кириллицы и иероглифов. Коимбра живет в эру супер-разнообразия! Tradução de Olga Solovova 
de desenvolver o conhecimento sobre os espaços, serviços e recursos existentes, promove-se a utilização autónoma das nossas bibliotecas.

Por experiência, enquanto cidadãos/ãs, sabemos que o primeiro contacto com as bibliotecas começa em criança, na biblioteca pública, fixa ou itinerante, ou na biblioteca escolar, seguindo-se o contacto com as bibliotecas académicas enquanto se "embarca" em projetos de vida que contemplam uma licenciatura, um mestrado, um doutoramento ou até um pós-doutoramento.

Como já mencionámos, procuramos aqui, partilhar as relações estabelecidas entre os doutorandos do CES, as Bibliotecas da Universidade de Coimbra, em geral, e a Biblioteca Norte|Sul, em particular. Não se trata, contudo, de apresentar um estudo minucioso, trata-se sim de mostrar como estes utilizadores representam e que valor dão à(s) "sua(s) biblioteca(s)".

Assim, no contexto das Comemorações dos 500 anos da Biblioteca da Universidade de Coimbra, partilhamos convosco alguns desses testemunhos dados pela diversidade de utilizadores das nossas bibliotecas, neste caso específico, e como já referido, alunos dos programas de doutoramento do Centro de Estudos Sociais em parceria com a FEUC, a FDUC, a FLUC, e o Instituto de Investigação Interdisciplinar (III), que falam das suas bibliotecas como: "quase "uma segunda casa" ..."; “...uma ferramenta preciosa para a investigação”; “.. um verdadeiro lugar de encontros"; “...da elevada competência técnica ..."; "...um acervo acumulado de conbecimento"; "...um espaço de encontros e desencontros..."; "... incomparáveis, pela magnitude, dimensão e tipo de repositório que lhes está confiado;”; “... um local "mágico” onde o silêncio fala alto.”; "um misto de magia e de estímulo.”; “...lugares onde se partilha o saber.”; “...fortalecendo os diálogos interculturais..."; "...personalizado, empático,"; "Espaços de resistências e de libertações"; “...espaço de encontros múltiplos, ..."; enfim," “... uma rede que cobre toda a cidade e a enriquece".

Partilho, agora, convosco alguns dos testemunhos dos nossos utilizadores: 


\section{Alexandra Martins Silva (Brasil)}

Na minha trajetória acadêmica, as bibliotecas da UC marcaram as diferentes etapas que atravessei entre o mestrado e o doutoramento. Destaco em especial, a biblioteca da FEUC e a biblioteca Norte/Sul do Centro de Estudos Sociais (CES), espaços fundamentais para que eu pudesse estudar, requisitar livros e trocar experiências. A importância de uma biblioteca durante a realização de um trabalbo acadêmico é imprescindivel e talvez por não ter podido usufruir desta experiência durante a licenciatura, guardo memórias maravilhosas da época que frequentei estas duas bibliotecas ao longo da realização do mestrado. Para um aluno(a) estrangeiro(a), a biblioteca é quase "uma segunda casa", na qual além de estudar, você tem a possibilidade de conbecer pessoas e partilbar as suas "angústias" acadêmicas.

Estas duas bibliotecas foram sem dúvida uma "segunda casa" para mim e me enriqueceram enquanto estudante e também enquanto pessoa, através da relação de amizade que mantive com os outros estudantes $e$ também com os seus funcionários. Os alunos da Universidade de Coimbra são privilegiados por terem a oportunidade de frequentar bibliotecas que além da riqueza bibliográfica, também são espaços repletos de bistória, como é o caso da Biblioteca Geral. Desta forma, enquanto uma aluna brasileira, sinto até hoje que estes espaços fizeram e fazem parte do meu processo de formação, independente do tempo que fique afastada de Coimbra”.

\section{Ana Neno (Portugal)}

A Biblioteca do CES tem sido uma ferramenta preciosa para a investigação, no âmbito da minha tese de doutoramento. Sempre que tive necessidade de consultar publicações não disponíveis nas bibliotecas da UC, os funcionários da Norte/Sul sempre se disponibilizaram para fazer os pedidos e as aquisições necessárias.

O sistema de digitalização de documentos oferecido pela Norte/Sul tem sido também imprescindível, facilitando a mobilidade, uma vez que me encontro ao abrigo de um acordo de cotutela e necessito com frequência de consultar publicações não disponíveis em Marrocos. Através deste ser- 
viço posso criar o meu próprio arquivo digital, sem impedimentos e levá-lo comigo para o estrangeiro.

Para mim a Norte/Sul é, não só, a melhor biblioteca da UC em termos de qualidade dos seus serviços, mas também pelas qualidades humanas do seu pessoal, que nos acolbem com um sorriso e com toda a disponibilidade e dedicação.

\section{Ana Raquel Matos (Portugal)}

As bibliotecas são, por definição, conjuntos de livros, lugares que nos remetem ao silêncio, à tranquilidade e a objetos ordenadamente dispostos de que se vai à procura. Durante quatro anos, porém, a biblioteca Norte|Sul foi, para mim, um espaço privilegiado de transgressão: porque me ofereceu leituras que me obrigaram a travar verdadeiros debates, diálogos entre abordagens e confrontos entre perspetivas que fizeram desse lugar tudo menos um espaço de silêncio, de silêncio interior; porque foi aí que desarrumei ideias, conceitos e perspetivas que jamais voltarão ao lugar onde ordenadamente as arrumava; porque mais do que um lugar de procura, foi, e ainda é, um verdadeiro lugar de encontros. Mas talvez a maior transgressão seja aquela que lhe faço caber no nome já que, sendo um espaço designado Norte|Sul, foi aí que viajei ao sabor da rosa-dos-ventos, passando por todos os pontos cardeais, navegando com sentido.

\section{Cristiano Gianolla (Itália) ${ }^{4}$}

A biblioteca da Universidade de Coimbra não é feita apenas de gabinetes, arquivos e salas de estudo. A melhor forma de a representar é através

${ }^{4}$ La biblioteca dell'Università di Coimbra non è fatta di stanze, archivi e sale di studio. Essa è meglio rappresentata da una rete che prende tutta la città e la arricchisce. La mia esperienza è di una sorprendente ricchezza di materiali, in modo particolare libri ed articoli di riviste scientifiche, che coprono le aree della conoscenza e non soltanto in merito alla letteratura principale. Per chi vuole approntare uno studio critico è fondamentale poter contare su questa rete ricca e dinamica, che continua ad evolversi col tempo. Il sistema informatico che permette di accederla è un ottimo supporto ma il vero valore aggiunto sono le persone che la curano e che vi lavorano. Esse mostrano un modo umano di fare scienza, anche quando questa passa da uno studio solitario. Un esempio su tutti sono Maria José, Acacio ed Ana della biblioteca Norte | Sul del Centro di Studi Sociali, che è il polo bibliotecario da cui più attingo. Ma come detto, la biblioteca dell'università di Coimbra è come una rete ed in essa gli echi migliori si odono ovunque. Tradução livre de Patrícia Branco 
da figura de uma rede que cobre toda a cidade e a enriquece. A minha experiência é a de uma surpreendente riqueza de materiais, em especial livros e artigos de revistas científicas, que abrangem todas as áreas do conhecimento e não só e apenas a literatura principal.

Para quem quer fazer um estudo crítico é fundamental poder contar com esta rede rica e dinâmica, que continua a evoluir com o passar do tempo. O sistema informático que permite aceder-lhe é um ótimo suporte, mas a verdadeira mais-valia é constituida pelas pessoas que a gerem e que ai trabalham. As mesmas demonstram uma forma bumana de fazer ciência, mesmo quando esta não passa de um estudo solitário. Um exemplo em relação a todos é o da Maria José, Acácio e Ana da Biblioteca Norte/ Sul do Centro de Estudos Sociais, que é Pólo bibliotecário que mais utilizo. Mas como referi, a biblioteca da Universidade de Coimbra é como uma rede na qual os melhores ecos se ouvem em qualquer parte.

\section{Hector Afonso Costa (São Tomé e Príncipe)}

Ora, eu sou utilizador da Biblioteca Norte/Sul, desde primeiros anos da minha Licenciatura em Sociologia até a data presente. O seu desenvolvimento gradual quer em termos do conforto espacial e térmico, quer em termos da qualidade e da quantidade dos livros temáticos disponíveis, quer em termos da elevada competência técnica dos seus profissionais, faz-me rotulá-la, como a melhor Biblioteca temática que já frequentei em Portugal, como Sociólogo.

\section{Isabel Tobon Giraldo (Colômbia) ${ }^{5}$}

A biblioteca da Universidade de Coimbra é um acervo acumulado de conbecimento que se reflete nos diferentes espaços da cidade que tem esse

5 La biblioteca de la Universidad de Coimbra es acervo acumulado de conocimiento que se refleja en los diferentes espacios de la ciudad con tiene ese encanto de fado que se renueva y a la vez conserva su profundidad y tradición. Desde la antigua Conímbriga y las grutas subterráneas abajo del museo Machado de Castro pasando por la espléndida Joanina hasta la Norte - Sur del la sede del Centro de Estudios Sociales en el Colegio San Jeronimo, la Universidad de Coimbra alberga la producción investigativa de académicos que se involucran con los esfuerzos emancipatorios del mundo. Como espacio de trabajo, las relaciones del interior de la biblioteca Norte -Sur con el paisaje de la ciudad propician el recogimiento intelectual y el pensamiento. La presencia amable de Maria José y Acacio 
encanto de fado que se renova e dialoga com profundidade e tradição. Desde a Conímbriga antiga, às grutas do Museu Machado de Castro passando pela esplêndida Joanina até à Norte |Sul, do Centro de Estudos Sociais, a Universidade de Coimbra alberga a produção científica de académicos que dialogam com os esforços emancipatórios do mundo.

Como espaço de trabalbo, a relação do interior da biblioteca Norte|Sul com a paisagem da cidade propicia o recolbimento intelectual e o pensamento. A presença amável da Maria José, do Acácio e da Ana são fundamentais para os processos de divulgação científica e de cooperação com os investigadores da Universidade. Permanecem em mim saudades da biblioteca, da Universidade, da maravilhosa cidade de Coimbra e de Portugal.

\section{Jonas Van Vossole (Bélgica) ${ }^{6}$}

\section{Ode á Biblioteca}

Comparemos a biblioteca ao espaço onde a colisão entre átomos leva á criação de novas partículas - às vezes desconbecidas; a biblioteca é um espaço de conbecimento como exponente de conflitos, diálogos e debates. É um espaço de encontros e desencontros, entre investigadores e fontes, novatos rebeldes e velhos clássicos, entre bistória e futuro, entre teoria e pratica.

Onde associamos a biblioteca aos livros, ironicamente é muitas vezes a fuga delas, uma fuga da sua solidão. Vê-la como buraco de verme, um

son fundamentales para los procesos de divulgación científica y de cooperación entre los investigadores de la Universidad. Permanecen en mí saudades de la biblioteca, de la Universidad, de la maravillosa ciudad de Coimbra y de Portugal. Tradução livre de Maria José P. F. Carvalho.

6 Ode aan de BibliotheekVergelijk het met de plaats waar de botsing tussen atomen leidt tot nieuwe partikels, de bibliotheek is een plaats van kennis, kennis als een exponent van conflict en debat. De bibliotheek is in eerste plaats die ontmoetingsplaats; een plaats van ontmoetingen tussen onderzoekers en hun bronnen, tussen nieuwelingen en grote klassiekers, tussen geschiedenis en heden, tussen theorie en praktijk. Waar we bibliotheken met boeken associeren is het ironisch genoeg vaak een vlucht weg van de boeken, de vlucht uit de eenzaamheid van het wetenschappelijk onderzoek. Zie het als een soort worm-hole, een shortcut tussen het universum van de interne dialoog tussen geest en en schrift naar een plaats van dialoog met mensen van vlees en bloed. Ooit het extravagante kenniscentrum van een imperium imperium is het vandaag een plaats van contacten met alle hoeken van de wereld, rond een simpele koffiemachine. Tradução de Jonas Van Vassole. 
atalbo entre o universo do diálogo interno entre a mente e a escrita $e$ o espaço de diálogo com pessoas de carne e osso; um dia o extravagante centro de conbecimento dum império, boje um sítio de contactos com gente de todos os cantos do mundo à volta duma simples máquina de café.

\section{José Eduardo Catalão Ferreira (Portugal)}

Quem, como eu, utiliza quase diariamente os recursos disponibilizados pelas bibliotecas, depara-se com duas dificuldades. A primeira é sentir-se à vontade para usar todos os recursos da biblioteca, poder circular e perguntar seja o que for às técnicas e técnicos que ali trabalbam, sem ter de estar preocupado se está a incomodar. A outra, muito importante, é poder manter um diálogo permanente e beneficiar da ajuda e orientação de quem ali trabalha. Daí que, a grande diferença entre uma biblioteca proactiva e uma biblioteca estática, é uma servir os interesses de quem a utiliza e a outra ser somente um balcão de atendimento e um depósito de livros e recursos bibliográficos. Neste sentido, não são só os espaços, a simpatia e a disponibilidade das pessoas que trabalham nas bibliotecas que importa, é muito mais o uso das competências específicas de quem lá trabalba em favor dos/as utilizadores/as - isso é que marca a diferença da Biblioteca $N \mid S$, do CES. Obrigado, pelo vosso excelente trabalbo!

Ainda assim, há que distinguir bibliotecas como a Biblioteca Geral da Universidade de Coimbra. Trata-se, pela sua dimensão, tipo de repositório e fluxo de utentes, de um caso aparte. Não seria justo, por isso, comparar esta biblioteca com outras de muito menor dimensão, em todos os aspetos, menos ainda, pensar que se trata somente de um depósito de livros e outros recursos bibliográficos. Além dos aspetos referidos, que são muito importantes e que se aplicam à maioria das bibliotecas, o tipo de profissionalismo e a gestão de uma biblioteca, como a Biblioteca Geral, são: por um lado, incomparáveis, pela magnitude, dimensão e tipo de repositório que lhes está confiado; e, por outro, pela responsabilidade institucional, enquanto imagem da Universidade de Coimbra. Uma e outra tarefas são, por isso, de uma responsabilidade incomensurável. Parabéns à Biblioteca da UC, pelos seus 500 anos, e parabéns a quem a dirige e lá trabalha, por conseguir cumprir, tão bem, esta difícil tarefa! 
Katia Cardoso (Cabo Verde) revela que:

"Não precisa saber tudo, só precisa saber como encontrar tudo". Este é um dos lemas dos bibliotecários.

Efetivamente, os bibliotecários sabem como e onde encontrar tudo. São melhores motores de busca que a Google. Mas também sabem tudo... tudo sobre como conquistar os utilizadores, com a sua competência, sentido de bumor, taça dos rebuçados...;)

Para comprovar o que estou a dizer basta, por exemplo, dar uma vista de olbos pela sessão dos agradecimentos das teses de doutoramento do CES concluídas nos últimos anos. Qual é o agradecimento comum a todas elas? "Aos bibliotecários da BNS...". À primeira vista até se pode pensar que se trata de um regulamento interno da instituição de acolbimento, mas não. Trata-se de um reconbecimento sincero de que se poderia ter feito a tese sem a BNS mas que não seria, definitivamente, a mesma coisa. A Universidade de Coimbra também não seria a mesma sem a sua Biblioteca. Parabéns pelos 500 anos. Que continue nos próximos 500 a acolber utilizadores ilustres e a ser um local "mágico" onde o silêncio fala alto.

\section{Maria João Guia (Portugal)}

As bibliotecas que a Universidade de Coimbra coloca ao dispor dos estudantes e académicos têm um misto de magia e de estímulo. Bem organizadas, atuais, com horários alargados, dispondo de funcionários de um profissionalismo e altruísmo exemplares, representam um dos pilares mais importantes para a ajuda da construção do conbecimento de quem as utiliza. Recordo da Biblioteca Geral a imensidão de uma partilha silenciosa de devoção por quem a frequenta. Sem precisar de trocar uma palavra, replica-se o incentivo de saber que, ao nosso lado, está outro alguém a munir-se das reflexões de quem já fez aquele percurso e que agora partilha o seu saber através dos livros ali depositados. As luzes de cada mesa cintilam brilhantes e enlaçam-se num afã plural de levar mais longe Coimbra, deixando uma marca indelével em quem aqui passa.

A Biblioteca Norte Sul é, para mim, um local único; só quem o vive pode compreender a profundidade com que marca os que têm o privilégio de coabitar as mesmas horas de entrega ao saber. Ali encontro os que 
partilham as mesmas angústias de quem dá à luz uma nova linha de pensamento; ali sei que quem está ao meu lado se dedica singularmente a ser único e a revestir o seu saber com o manto de Coimbra; ali entrego hoje os meus livros, sentindo o maior orgulbo em imaginá-los folbeados por quem quer fazer o percurso audaz e resiliente de encontrar caminhos por percorrer; ali, toda a resposta que nos é dada nos momentos de 'psicose' produtiva, em que as ideias brotam e se entrecruzam, multiplicando-se no nosso íntimo, selvagens, adolescentes e ganhando vida própria, é sentida como um bálsamo de aconchego.

Para a eternidade perduram as memórias daquele livro que para nós foi único, entregue no momento certo em que a produção corria o risco de se esfumar, etérea e insinuante...

\section{Martina Matozzi (Itália)}

Não é fácil, em Coimbra, encontrar uma biblioteca tão provida, atualizada e acolhedora como a Biblioteca Norte/Sul do Centro de Estudos Sociais. Além dos materiais disponíveis nas instalações, a mais-valia deste espaço são as pessoas: as que vão lá para estudar e investigar, mas sobretudo as que lá trabalham, seres que sabem acerca dos livros, conbecem os utilizadores e partilham conbecimento e experiência.

As bibliotecas não são exclusivamente espaços taciturnos onde se catalogam e guardam livros, mas também lugares onde se partilha o saber. Como utilizadora, posso dizer que grande parte do meu trabalbo de investigação foi e está a ser realizado graças à riqueza bumana e científica que a biblioteca Norte/Sul oferece.

\section{Natacha Guala (Argentina) ${ }^{7}$}

A Biblioteca Norte $\mid$ Sul do Centro de Estudos Sociais da Universidade de Coimbra constitui um espaço único para o desenvolvimento da ativi-

\footnotetext{
7 La Biblioteca Norte/Sul del Centro de Estudos Sociais de la Universidad de Coimbra constituye un espacio único para el desarrollo de la actividad académica que como estudiantes de doctorado e investigadores realizamos. El dinamismo y la vitalidad creativa generados en espacios de intercambio abiertos, como los seminarios y mesas de debate, permiten y estimulan la reflexión compartida y el aprendizaje a partir de las experiencias que con-
} 
dade académica que, como estudantes de doutoramento e investigadores, realizamos. O dinamismo e a vitalidade criativa gerados em espaços de intercâmbio abertos, como os seminários e encontros de debate, permitem e estimulam a reflexão partilhada e a aprendizagem a partir de experiencias que ali se congregam de partes distintas do mundo, neste espaço plural de trabalbo e formação.

A facilidade de acesso aos materiais disponíveis na Biblioteca, tanto fisicamente como em formato digital, gera muita fluidez e comodidade no trabalbo, preparando também para uma abordagem intuitiva às novas e variadas fontes e referências de conbecimento e estudo. Desta forma, a boa disposição que os dedicados trabalhadores da Biblioteca Norte|Sul têm para quem escolhe trabalhar ali imprime um entusiasmo ao ambiente que nos convida a apropriarmo-nos do espaço e a voltar sempre.

Por estas razões, dou um valor profundo à oportunidade de continuar a minha formação pessoal e profissional neste espaço enriquecedor, desejando que cada vez sejam mais os colegas e companheiros que, ocupados em estudar a participação em experiências sociais emancipatórias (características das linhas de investigação do CES) se acerquem da Biblioteca Norte|Sul, fortalecendo os diálogos interculturais necessários para a construção de uma ciência social comprometida com a mudança social.

\section{Nuno Grancho (Portugal)}

A biblioteca Norte/Sul cumpre a função de expandir o conbecimento, pois diversifica o acervo e é um lugar de descoberta. Também na Norte/Sul é possível valorizar a produção própria dos alunos e estimular a leitura apenas pelo seu próprio prazer. Não dispenso a Norte/Sul.

A BGUC é para mim a referência mundial em termos históricos e no lato senso. É o lugar onde está depositado o original da primeira repre-

fluyen desde distintas partes del mundo en este espacio plural de trabajo y formación. La facilidad de acceso a los materiales disponibles en la Biblioteca, tanto físicamente como en formato digital, genera mucha fluidez y comodidad en el trabajo, habilitando además el acercamiento intuitivo a nuevas y variadas fuentes y referencias de conocimiento y estudio. Asimismo, la buena predisposición que los dedicados trabajadores de la Biblioteca Norte/ Sul tienen para con quienes elegimos trabajar allí, imprime una calidez al ambiente que invita a apropiarse del espacio y regresar siempre. 
sentação de Diu, o mote da minha tese (Roteiro de Goa a Dio, D. João de Castro, 1531). Não dispenso a UCBG.

\section{Sandra Guerreiro Dias (Portugal)}

A minha experiência enquanto investigadora na biblioteca Norte/Sul é a melhor possível. Nela encontrei, ao longo dos já vários anos de pesquisa, o melhor ambiente de trabalho de todas as bibliotecas da Universidade de Coimbra. Este facto prende-se com vários aspetos: a ergonomia do local, bastante acolhedor, arrumado, confortável, iluminado, o material disponível, bastante atualizado e especializado e, sobretudo, os profissionais que nela trabalham. O atendimento é personalizado, empático, verdadeiramente interessado nas solicitações que lhes são dirigidas, profissional. Por várias vezes tive a oportunidade de encontrar soluções e ter acesso a pistas de pesquisas fundamentais para o meu trabalbo por via da ajuda e disponibilidade destes profissionais. Esta experiência que descrevo contrasta largamente com a experiência que tenbo nas restantes bibliotecas da universidade, pelo que julgo que o seu exemplo deve ser amplamente divulgado, valorizado e reforçado.

\section{Sandra Silva Carvalho (Portugal)}

As bibliotecas são feitas de conhecimentos e saberes, de pessoas e de partilhas. Entre os que escrevem e os que leem acontece o perpétuo movimento das aprendizagens, dos projetos e dos sonbos. Que autor nunca leu, ou foi inspirado por outros? E que leitor nunca escreveu ou sonbou com as suas leituras? Espaços de resistências e de libertações, as bibliotecas têm este papel fundamental na construção e desconstrução dos saberes $e$ na criação das condições para tornar os sonbos possíveis.

A Biblioteca da Universidade de Coimbra cumpre agora 500 anos deste perpétuo movimento.

Há uns meses atrás, na minha caminhada para o doutoramento, resolvi vir morar para Coimbra, e que aposta tão ganha! Ganha por muitos motivos. Ganha pela riqueza bibliográfica que encontrei, pelas pessoas que reencontrei, por aquelas que entretanto conbeci e com quem tanto partilhei. Os lugares destes encontros foram invariavelmente as bibliote- 
cas da Universidade, nomeadamente a Biblioteca Geral e, em especial, a Biblioteca Norte|Sul do Centro de Estudos Sociais. Aqui encontrei uma fonte quase inesgotável de recursos e profissionais excecionais. Dedicados, amáveis e sempre, sempre disponíveis para me ajudar e orientar na minha busca. À Biblioteca Geral e à Universidade de Coimbra apenas desejo que se cumpram pelo menos mais 500 anos de vida. Os tempos difíceis que atravessamos são desafiadores mas a Universidade não pode vacilar.

\section{Tulio Muniz (Brasil)}

A Biblioteca N/S do CES é um espaço de encontros múltiplos, não apenas de saberes e pesquisas, mas de pessoas de diferentes contextos que, em comum, têm a busca por reflexões no campo contra-begemónico. Nesse sentido, a N/S é um espaço paradoxalmente diferenciado, pois seu público é, ao mesmo tempo que diversificado, é também afinado no sentido de busca da construção do conbecimento académico. E, evidente, os funcionários da N/S são os grandes responsáveis pela permanência e manutenção desse arejamento das ideias, onde o rigor biblioteconómico se faz acompanhar de alegria e estímulo aos pesquisadores, recebidos com competência acompanhada de bons afetos e sorrisos.

\section{Reflexão final}

Segundo a História e Memória da Biblioteca da Universidade de Coimbra ${ }^{8}$ : "Em Coimbra, a biblioteca continuaria a ser pensada pelos Estatutos de 1544 com livros encadeados, com correntes, varões e fechaduras". Estes cadeados, correntes, varões e fechaduras foram posteriormente substituídos por armários fechados à chave ou a cadeado. O saber estava lá mas estava encarcerado.

Na Biblioteca Norte|Sul (BNS), em Novembro de 2002, a minha primeira atividade foi precisamente "abrir" a coleção e permitir o livre acesso, um

8 BIBlioteca GERAL DA UNIVERSIDADE DE COIMBRA - Quinhentos anos de Biblioteca da Universidade de Coimbra. História e Memória: do livro "encadeado" até ao empréstimo domiciliário. [Em linha]. Disponível na WWW em: <URL: http://www.uc.pt/bguc/500anos/ Apresentacao>. 
pequeno contributo para desencarcerar as coleções e facilitar o encontro com o conhecimento imprevisto.

Os testemunhos dos nossos utilizadores revelam que as nossas bibliotecas são muito mais do que "conjuntos de livros", espaços onde os "objetos" se encontram "ordenamente dispostos". Elas são lugares de "estímulo à leitura", "de troca de experiências", "pilares ... importantes para a ajuda da construção do conhecimento", "lugares de perpétuo movimento das aprendizagens" e "têm um papel fundamental na construção e desconstrução dos saberes e na criação das condições para tornar os sonhos possíveis". Elas são instrumentais para que as metamorfoses entre o não-saber e a expansão do conhecimento se operem.

Durante 5 séculos, a BUC esteve em permanência histórica como um espaço incontornável onde gerações após gerações de alunos, professores e investigadores, nacionais e estrangeiros, buscaram e continuam a buscar conhecimento, tal como comprova os testemunhos apresentados. Se ao longo da sua existência a BUC demorou algum tempo a "abrir" as portas, hoje, resta-lhe dinamizar as metamorfoses que garantam ainda maior acesso ao conhecimento às gerações atuais e às vindouras!"

E termino com as reflexões de Maria João Guia.

"As luzes de cada mesa cintilam brilhantes e enlaçam-se num afã plural de levar mais longe Coimbra, deixando uma marca indelével em quem aqui passa”.

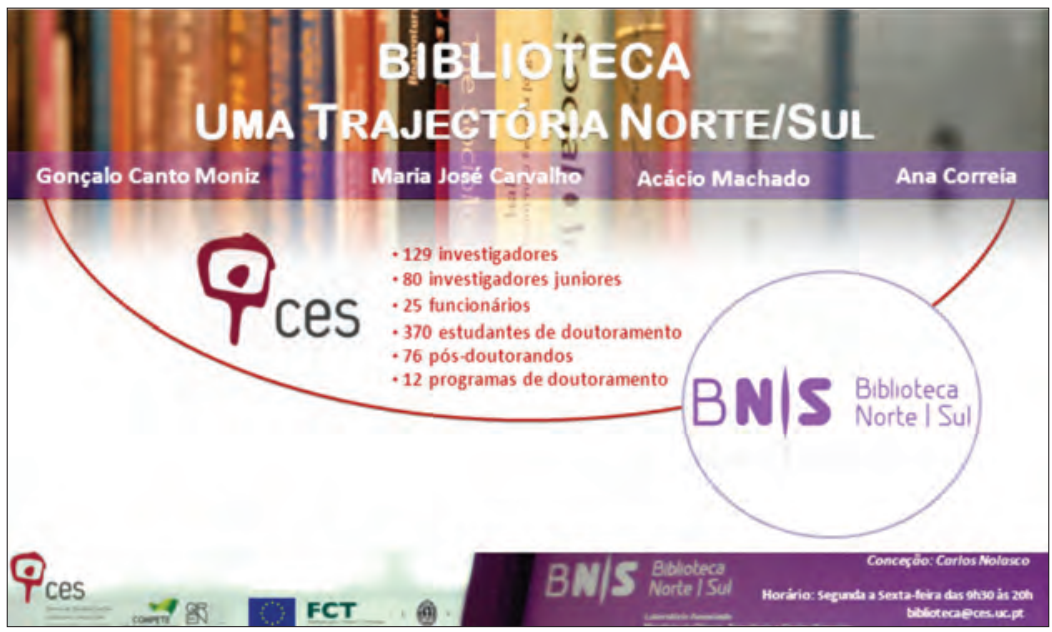




\section{Referências bibliográficas}

BIBLIOTECA GERAL DA UNIVERSIDADE DE COIMBRA - Quinhentos anos de Biblioteca da Universidade de Coimbra: uma celebração justa e necessária. [Em linha]. Coimbra: BGUC. [Consult. 5 jan. 2014]. Disponível na WWW em: <URL: http:// Www.uc.pt/bguc/500anos/Apresentacao>.

BIBLIOTECA GERAL DA UNIVERSIDADE DE COIMBRA - Quinhentos anos de Biblioteca da Universidade de Coimbra. História e Memória: do livro "encadeado" até ao empréstimo domiciliário. [Em linha]. Coimbra: BGUC. [Consult. 5 jan. 2014]. Disponível na WWW em: <URL: http://www.uc.pt/bguc/500anos/Apresentacao>. 
José Augusto Cardoso Bernardes é Professor da Faculdade de Letras da Universidade de Coimbra e Diretor da Biblioteca Geral da Universidade

Ana Maria Eva Miguéis é coordenadora do Serviço Integrado das Bibliotecas da Universidade de Coimbra

Carla Ferreira é bibliotecária nos Serviços de Biblioteca e Documentação da Faculdade de Letras da Universidade de Coimbra. 


\section{Série Documentos}

Imprensa da Universidade de Coimbra

Coimbra University Press

2015

C •

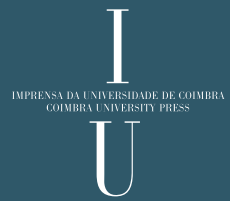

